\title{
Convergence of Stock Futures Markets - An Analytical Study of Indian Stock Markets
}

\author{
Rajeesh Viswanathan*, Jintu George*, D Lazar, Jahira Parveen
}

\begin{abstract}
Trading on stock futures was introduced in India on $9^{\text {th }}$ November 2001. Initially the contracts are settled in cash and in 2010 July 15 the SEBI allowed the exchanges to choose the physical settlement system for futures trading in stocks, with an aim to put the Indian futures and settlement system at par with other developed markets. So the stocks can be settled either through the cash or physical delivery. The study aims to investigate the price convergence between the spot and the futures prices and its effect on cash settled and the physical delivery in single stock futures. The study finds that there is an efficient convergence of both the market under the Physical delivery and its persistence throughout the contract period while compared with the cash settled single stock futures.
\end{abstract}

\section{INTRODUCTION}

Convergence is an essential phenomenon in derivative markets that ensures that spot prices and expectations about future movement in spot prices move in tandem with each other. The derivative markets achieve convergence by means of cash settlement of futures contracts on spot price at the time of maturity; some others drive convergence by means of pressure of delivery at the time of maturity. In a derivatives market, the final settlement of derivative contract at the time of its maturity could be done through either physical delivery of the underlying asset or through cash settlement system. Though there are different methods of settlements, many markets follow cash settlement system instead of physical delivery of underlying asset at the date of expiration taking into consideration the easiness, convenience and to avoid other costs associated with the delivery of the underlying asset. Other issues associated with delivery like lack of liquidity in the underlying cash markets, lack of a vibrant SLB market, etc., also support the need for cash settled derivative contracts.

Conventionally, on the date of expiration, the futures market settles contract with physical delivery of underlying asset (except index futures and similar intangible assets) as the means of final settlement of a derivative position. In cash settlement system, the underlying asset is not transferred physically but a derivative position is settled with the settlement price set equal to a specified cash market price and

Revised Manuscript Received on July 05, 2019.

Dr. Rajeesh Viswanathan, Assistant Professor, Dept of International Business, School of Management, Pondicherry University, Pondicherry. Jintu George, Research Scholar, Dept of International Business, School of Management, Pondicherry University, Pondicherry.

Dr. D Lazar, Professor, Dept of Commerce, School of Management, Pondicherry University, Pondicherry.

Dr. Jahira Parveen, Faculty of Management, SRM Institute of Technology, Chennai.

\footnotetext{
*- Equal contribution.
}

the difference (either gain or loss) in price is paid/received in cash. Such a market assumes that there are arbitragers who would take care of the price differences that may exist between the derivative markets and the relevant underlying cash market instrument. It was observed by the technical committee of the IOSC that in a derivative market the settlement and delivery procedure would reflect the underlying physical market and helps in promoting reliable pricing relationships and price convergence which should be regularly evaluated to ensure that determined standards are met.

One of the most debated area with regards to measuring effectiveness and their vulnerability to speculation and manipulation of two modes of settlement in derivative contract i.e., cash and physical settlement.

It was learnt that physical settlement facilitates the link to the real markets of underlying securities. Though there are possibilities to distortions such as "short squeezes. Cash settlement provides the advantage of avoiding the problem of delivery costs there by lowering the effectiveness of market manipulations such as cornering and squeezing

In futures contracts, the delivery process helps to tie-up the futures and cash prices together; in other words it ensures better convergence of futures market and the underlying cash market. In a perfect market with cost-effective delivery at one location on a given date, arbitrage should force futures price to converge on expiry. If futures price remain above cash price on maturity, the cash asset is bought, futures contract sold and delivery would be made (in case of delivered contract). If the cash price is more than futures on maturity, then futures are bought and the buyer stands for delivery. This type of arbitrage would always prevent the 'law of one price' from being violated but at a cost that is associated with enablement of delivery of underlying assets. When the delivery mechanism functions effectively in a derivative market, a minimal amount of delivery would be sufficient enough to ensure effective delivery since long and short futures position holders would be indifferent to offsetting their positions rather than making or taking delivery.

Only few papers have examined empirically the advantage and disadvantage of physical as well as cash settlement system in derivative market. Out of this the study on stock futures are scanty and the results are mixed.

In cash settlement system one can see that the settlement price is fixed based on the index value or some other reference values and many authors like Edward and MA (1994), Garbage and Silber (1983) argue that lower vulnerability to corners is one of the advantages of cash settlement

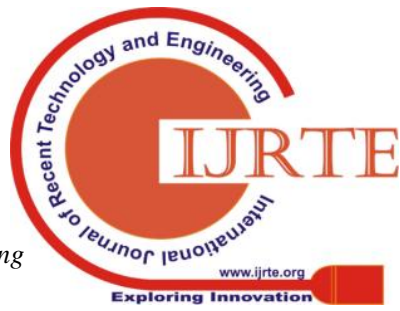


system. Lien \& Tse (2003), titled "A Survey on Physical Delivery versus Cash Settlement in Futures Contracts" found that, cash settlement is the best alternative to physical settlement of the contracts. Rich and Leuthold (1993) find that convergence between futures and cash prices has improved in the cash settlement system and there by the hedging effectiveness of the futures contracts. At the same time they also find minor improvement in basis variability and a significantly smaller basis after cash settlement. Rich and Leuthold (1993) find very low improvement in basis variability but a significantly smaller basis after introducing the cash settlement system. Lien (1989) in his study points that if the variances are smaller for the futures contracts then the cash settlement is chosen or else the physical delivery is preferred.

Literature on the cash settlement system elucidates the risk of price manipulation in derivative market. Kumar and Seppi (1994) noted that cash settlement system have significant welfare implication as it has been misused for price manipulation of spot trading leads to improve the settlement price but it may hurts futures noise traders. The increased spot liquidity of cash settlement systems benefits the informed traders and the spot noise traders.

Lien and Yang (2003) investigated improvements in the price discovery mechanism of futures prices and the dependence from share market to share futures market by using ISF contracts of Australia under the cash and physical delivery settlement methods and found that after switching from cash settlement to the physical delivery system the information flow was increased from the spot market to the futures market and it helps to reinforce the informational role of the spot market. The study of Lien a Yang (2004) examined return volatility and hedging performance with cash and physical settlement system and the correlation of the two markets on Australian individual stock and its futures market and found that the market is more volatile and the effectiveness of hedging increased for most of the futures contract in physical settlement system and is more in those futures contract, those established recently, but they did not find any effect on futures return.

Another widely discussed issue in the derivative market is the expiration day effect and is the effect on securities prices, abnormal return and volume, as the traders adjust their positions shortly before expiration of the contracts during the last hour of trading on expiration days. Bollen \& Whaley (1999) noted that the expiration-day effects was used by the arbitrageurs in the cash settlement to liquidate their stock positions and their result suggests that the informational role was strengthen after the stock was switched from cash settlement to physical delivery in Australian stock market. Lien and Yang (2005) carryout a study on expiration-day effects of stock options traded in Australian Stock Exchange with the effect switching of settlement method from cash settlement to the physical delivery. By considering return, trading volume, volatility, and temporary price changes of individual stock and find that the return and volatility of the underlying stocks has a very significant impact on the option expiration along with the change in the settlement method; while the effect of option expiration has very less effect to the trading volume. They also noted that physical delivery simplify the expiration-day effects because arbitrageurs doesn't have any positions on the expiration days. Lien and Yang (2003) noted that during the cash settlement periods the lagged spot and futures returns are influencing the current futures return whereas such influence are not present in the delivery settlement system.

Review of literature reveals that both cash and physical delivery are advantageous as a settlement system in single stock futures. Further most of the studies have examined the effect of cash and physical delivery system is related only to commodity market and very few studies found in single stock futures as against many studies on Index futures. There are only few studies in India which compares cash settlement with physical delivery. Most of the studies are from foreign markets not from India and that too without any comparison. Studies in India express the similar results of foreign studies. These studies are only of academic value and largely lack policy imperatives for improving convergence in the derivatives markets. Therefore this study makes an attempt to find empirical evidences by comparing cash and physical settlements in Indian single stock futures.

\section{Data and preliminary analysis}

The Securities Exchange Board of India had allowed exchanges to choose physical settlement system for futures and options trading in stocks with an aim to put Indian futures and settlement system at par with other developed markets. As per the new system, stock exchanges are permitted to adopt any one of the following mode of settlement of derivatives contracts: i) Cash settlement for both stock futures and stock options or ii) Physical delivery (by delivery of underlying stock) for both stock futures and options or iii) Cash settlement for stock futures and physical settlement for stock options or iv) Physical settlement for stock futures and cash settlement for stock options (vide SEBI Circular dated July 15,2010$)$. With the specific circular many companies choose the mode settlement as physical delivery and some companies continued with cash settlement.

Table 1 report name and codes of the companies uses cash settlement and physical delivery which is used for the study. Daily closing prices of spot and its corresponding futures of single stocks which are traded in S\&P BSE sensex were collected by using Bloomberg data base for a period from 1 stJanuary 2014 to the $30^{\text {th }}$ August 2018. The futures contract traded in Indian market are expired with a period of 3 months, with far month, middle month and near month contracts. The study used generic futures of near month contracts which are rolling over to the expiry. The futures data were matched to the spot and selected those having both the data points for a day, a total of 1019 to 1052 observations are used for a pair of 10 stocks to study the convergence analysis.

Table 1. Stocks included in the study

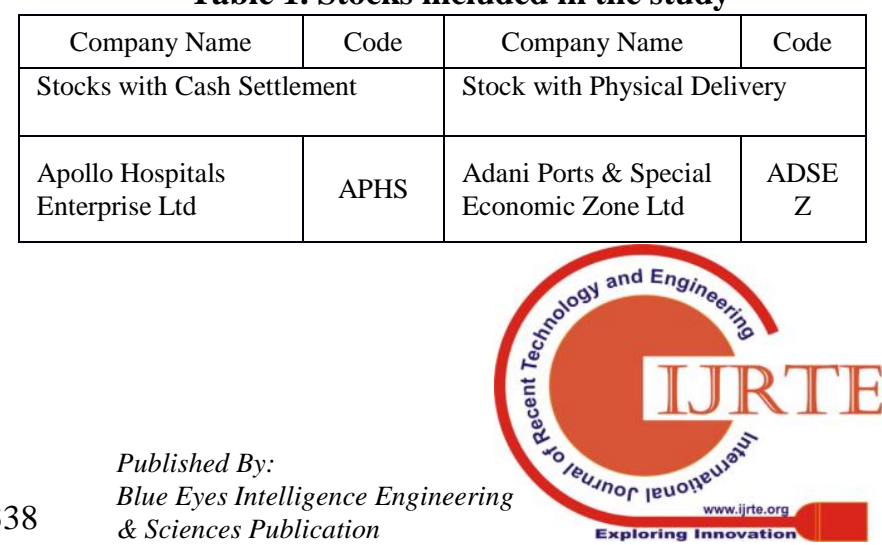




\begin{tabular}{|c|c|c|c|c|c|c|c|}
\hline $\begin{array}{l}\text { Glenmark } \\
\text { Pharmaceuticals Ltd }\end{array}$ & GNP & Asian Paints Ltd & APNT & $\begin{array}{l}\text { Oil \& Natural Gas } \\
\text { Corp Ltd }\end{array}$ & ONGC & NTPC Ltd & NTPC \\
\hline $\begin{array}{l}\text { Mahindra \& } \\
\text { Mahindra Financial } \\
\text { Services Ltd }\end{array}$ & MMFS & Coal India Ltd & COAL & $\begin{array}{l}\text { Power Grid Corp of } \\
\text { India Ltd }\end{array}$ & PWGR & $\begin{array}{l}\text { Sun Pharmaceutical } \\
\text { Industries Ltd }\end{array}$ & SUNP \\
\hline
\end{tabular}

\begin{tabular}{|c|c|c|c|c|c|c|c|}
\hline Company & Returns & Mean & Maximum & Minimum & Std.Dev. & Skeweness & Kurtosis \\
\hline \multicolumn{8}{|c|}{ Cash Settled stocks } \\
\hline \multirow{2}{*}{ APHS } & Spot & 0.000032 & 0.018 & -0.013 & 0.00270 & 0.429 & 5.816 \\
\hline & Futures & 0.000032 & 0.018 & -0.013 & 0.00280 & 0.461 & 5.829 \\
\hline \multirow{2}{*}{ GNP } & Spot & 0.000037 & 0.016 & -0.026 & 0.00304 & -0.595 & 9.733 \\
\hline & Futures & 0.000037 & 0.017 & -0.026 & 0.00312 & -0.489 & 9.645 \\
\hline \multirow{2}{*}{ MMFS } & Spot & 0.000078 & 0.031 & -0.017 & 0.00412 & 0.597 & 6.818 \\
\hline & Futures & 0.000078 & 0.033 & -0.018 & 0.00425 & 0.661 & 7.388 \\
\hline \multirow{2}{*}{ ONGC } & Spot & -0.000008 & 0.018 & -0.024 & 0.00355 & -0.292 & 7.928 \\
\hline & Futures & -0.000010 & 0.015 & -0.026 & 0.00349 & -0.314 & 7.397 \\
\hline \multirow{2}{*}{ PWGR } & Spot & 0.000137 & 0.015 & -0.012 & 0.00269 & 0.302 & 5.482 \\
\hline & Futures & 0.000136 & 0.014 & -0.012 & 0.00277 & 0.387 & 5.291 \\
\hline \multicolumn{8}{|c|}{ Physically Delivered stock } \\
\hline \multirow{2}{*}{ ADSEZ } & Spot & 0.000170 & 0.023 & -0.026 & 0.00438 & 0.245 & 7.986 \\
\hline & Futures & 0.000170 & 0.025 & -0.026 & 0.00451 & 0.333 & 7.940 \\
\hline \multirow{2}{*}{ APNT } & Spot & 0.000148 & 0.018 & -0.013 & 0.00240 & 0.340 & 8.024 \\
\hline & Futures & 0.000148 & 0.019 & -0.011 & 0.00247 & 0.462 & 7.878 \\
\hline \multirow{2}{*}{ COAL } & Spot & 0.000001 & 0.020 & -0.018 & 0.00313 & 0.166 & 7.012 \\
\hline & Futures & 0.000000 & 0.019 & -0.018 & 0.00318 & 0.214 & 6.805 \\
\hline \multirow{2}{*}{ NTPC } & Spot & 0.000044 & 0.020 & -0.025 & 0.00325 & -0.313 & 8.765 \\
\hline & Futures & 0.000044 & 0.015 & -0.026 & 0.00337 & -0.370 & 7.795 \\
\hline \multirow{2}{*}{ SUNP } & Spot & 0.000021 & 0.016 & -0.024 & 0.00306 & -0.703 & 11.816 \\
\hline & Futures & 0.000020 & 0.016 & -0.024 & 0.00309 & -0.593 & 11.364 \\
\hline
\end{tabular}

current basis is more positive than the expected (average)

The table (2) reports the summary statistics of 10 pairs of return series. The mean, minimum, maximum, standard deviation, Skeweness and kurtosis are reported. Convergence and its persistence could be seen during the entire nearby futures contract period. It is noticed that the stocks with the physical delivery having higher standard deviation compared to the other which specifies that both the spot and futures market were more volatile in the physical delivery period, the kurtosis also shows a similar pattern like the std. dev.

Before discussing the model, we perform the unit root test and cointegration analysis. The price series are converted into the natural logarithm where $p_{s t}$ and $p_{f t}$ denotes the natural logarithm spot and futures prices at time $t$ respectively. The Augmented Dickey Fuller (ADF) applied to the $p_{s t}$ and $p_{f t}$. The price series have unit root where as its first difference (returns of spot and futures) have the stationarity. The table is not reported due to the space constraints but are available upon request. If the futures and spot prices having unit root means the prices are not stationary but returns of prices series are stationary, the cointegration concept become relevant which lays the cost- of -carry theory. The Engle and Granger (1981) is used to test the cointegration relationship

\section{2.a Basis analysis}

The simple difference between the cash and future price is known as basis. It refers to the difference between the price of futures contract and the underlying cash price at a given point in time. So we can define the basis as $\mathrm{B}_{t}=P_{s t}-P_{f t . .}$ A negative basis implies the future price is higher than cash price, and a positive basis implies futures price is less than cash price; basis can be either negative or positive. It is said that the basis is "stronger" or "narrower" than the normal basis when the

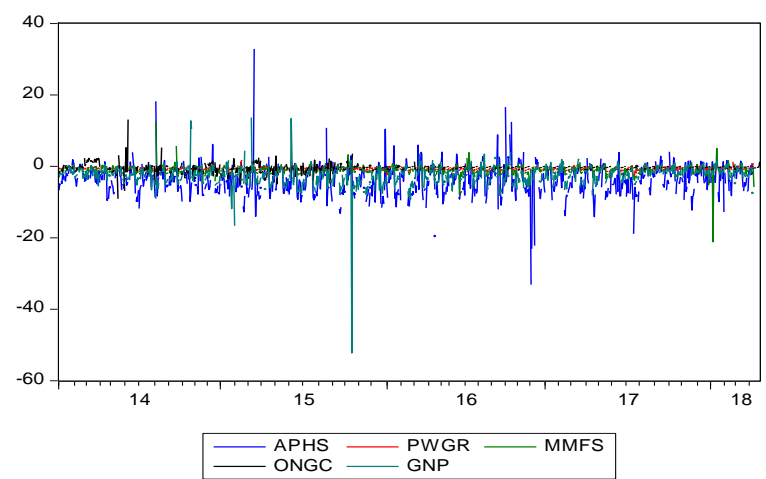

Figure 1: Basis of stocks with cash settlement

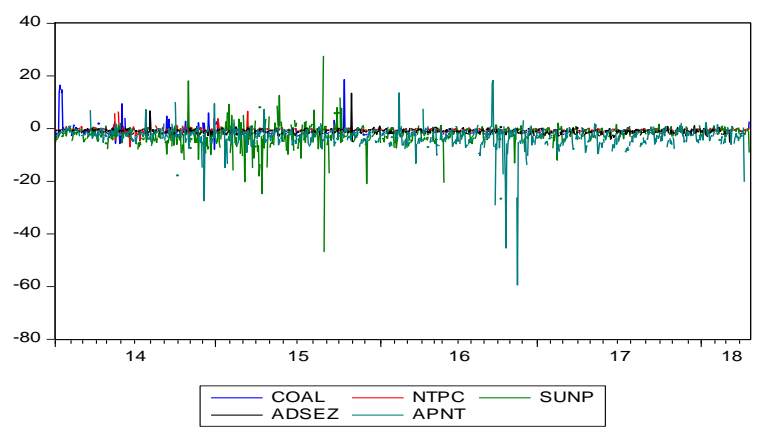

Figure 2: Basis of Stocks with Physical Delivery

Larger basis are found in most of companies with cash settled which have greater deviations to the negative side. Analysis of basis behaviour of derivative contracts with cash settlement indicates that either it does not converge or even if converges, it is basically to break the path to take some

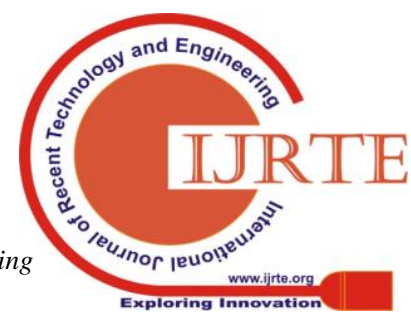


other directions. So, the convergence is usually taking place only on the last day so it is seen that the cash settled contract are not having stability. The basis graph of the physical delivery shows a negative (but smaller than cash settled stocks) and lesser deviation from the midpoint. So the convergence can take easily on the expiration day. This may be due to the regulations or the terms and conditions of contract which could attribute to the fear of delivery that may exist in the minds of derivative participants.

\section{Long run relationship}

Auto Regressive Distributed Lag Model (ARDL) is used for the given current sample size as it provides a convenient way to deal with long run relationship and short run dynamics which used to estimate jointly, by focusing on the dynamics of one single equation. The ARDL model was developed by Pesaran et.al (2001). The ARDL model can use the variable whether it is I (0) or I (1) or fractionally integrated but not I

Table no.3 F-Statistics for testing the existence of cointegration

\begin{tabular}{crc|ccl}
\hline \multicolumn{3}{c}{ Cash Settlement } & \multicolumn{3}{c}{ Physical Delivery } \\
\hline & F-statistic & Decision & F-statistic & Decision \\
\hline APHS & $152.357^{* * *}$ & cointegration & ADSEZ & $165.959^{* * *}$ & cointegration \\
GNP & $156.380^{* * *}$ & cointegration & APNT & $278.459^{* * *}$ & cointegration \\
MMFS & $172.644^{* * *}$ & cointegration & COAL & $162.557^{* * *}$ & cointegration \\
ONGC & $62.1744^{* * *}$ & cointegration & NTPC & $83.445^{* * *}$ & cointegration \\
PWGR & $117.996^{* * *}$ & cointegration & SUNP & $79.757^{* * * *}$ & cointegration \\
\hline
\end{tabular}

Dependent variable LNFUTURES

At $1 \%$ lower bound critical value $=6.84$ and Upper Bound Critical value $=7.84(* * *)$

At $5 \%$ lower bound critical value $=4.94$ and $\mathrm{Upper}$ Bound Critical value $=5.73(* *)$

At $10 \%$ lower bound critical value $=4.04$ and Upper Bound Critical value $=4.78(*)$

(2) integration, where the other tools such as johansen's cointegration and the Engle granger cointegration use only the same integration level. In ARDL model there is also no need for the prior investigation of unit root and the estimates from the ARDL are unbiased and efficient because it will distinguish the dependent and the explanatory variables and avoid the problems related to the presence of serial correlation and the endogenity.

In the study we uses a two step procedure, firstly we estimate the long run relationship between the variables and if there exist a presence of long run relationship, the short run and long run parameters are estimated in the second stage. The unrestricted error correction model (UECM) can be used to describe the long run relationship using the bound test in ARDL model.

$$
\begin{gathered}
\Delta P_{f t}=\alpha_{f o}+\sum_{i=1}^{k} \beta_{f i} \Delta P_{f, t-i}+\sum_{j=1}^{k} \gamma_{f j} \Delta P_{s, t-j} \\
+\theta_{f 1} P_{f, t-1}+\theta_{f 2} P_{s i t-1}+\epsilon_{f t}
\end{gathered}
$$

In the equation $\mathrm{P}_{\mathrm{ft}}$ is the natural $\log$ of futures price, $\mathrm{P}_{\mathrm{st}}$ is the natural log of spot price, $\mathrm{k}$ is the number of lags. The F-Statistic can be used to find the existence of the long run relationship, the computed value is compared with lower and the upper bound critical values reported in pesaran et.al
(2001). The null hypothesis $\mathrm{H}_{0:} \theta_{f 1}=\theta_{f 2}=0$, i.e. nonexistence of long run relationship is rejected if the calculated $\mathrm{F}$ value is more than the critical values. After estimation of the long run cointegration by using bound test (equation 1), the next step is to establish ARDL $(m, n)$ Model i.e. equation (2). The lags (k) selected in equation (1) is retained for the choosing the maximum lag in equation (2). The lags are chosen according to AIC or SIC criteria for the best ARDL model specification.

$$
P_{f t}=a+\sum_{i=1}^{m} b_{i} P_{f t-1}+\sum_{i=0}^{n} c_{i} P_{s t-1}+u_{t}
$$

Combination of long term and short run relationship in a single model helps to attain more reliable results, so in second stage, ARDL model is to estimate the long run and its error correction coefficients. The second equation can be simplified as

$$
P_{f t}=\lambda a+\lambda \sum_{i=0}^{n} c_{i} P_{s t}+\lambda u_{t}
$$

Where,

$$
\lambda=\frac{1}{1-\sum_{i=1}^{m} b_{i}}
$$

The (ECM-1) in the ARDL model derived from a cointegration equation represent the one period lagged error correction term. The coefficient value present in the ECM-1 shows the speed of convergence or adjustment towards the long run. A negative coefficient with one percent level significance is expected for the model to facilitate a useful meaning for the findings of long term relationship. The error correction model used in ARDL $(m, n)$ model can be specified as,

$$
\begin{aligned}
\Delta P_{f t}= & b_{o}+\sum_{i=1}^{m-1} b_{i} \Delta P_{f i t-i}+\sum_{i=0}^{n-1} c_{i} \Delta P_{s i t-i} \\
& -\left(1-\sum_{i=1}^{m} b_{i}\right) \operatorname{ECM}_{t-1}+\epsilon_{i}
\end{aligned}
$$

Where,

$$
E C M_{t-1}=P_{f t}-\lambda \sum_{i=0}^{n} c_{i \bar{s}} P_{s t} \text { (6) }
$$

\section{Empirical results,}

Since all the variables have stationarity at first difference and none of the series is at I (2). Bound test is used for examine the cointegration relationship between the futures and spot market.

The null hypothesis of nonexistence of long run relationship is rejected at one percent level significance for all companies. The table 3 shows that the dependent variable is $\log$ futures and it summarises the existence of long run cointegration between futures and spot among all the 10 companies.

Since the spot and futures markets are cointegrated, the long run relationship can be estimated through the ARDL 
model, and the Akaike Information Criterion (AIC) is used for the estimation of equation no. 2 and which is reported below.

All the coefficients are positive and significant at $1 \%$ level. It also suggests that although both markets may be in disequilibrium during the short run, such deviations are very quickly corrected through the arbitrage process and it is a necessary condition for market efficiency. Market efficiency depends on the speed with which the market removes disequilibrium and maintains a balanced relationship between the spot and future market.

Table no. 4 Estimated Long Run Coefficients using the ARDL Approach of stocks with cash settlement and physical delivery

\begin{tabular}{|c|c|c|c|c|}
\hline & Regressor & Coefficient & T-Ratio & Model \\
\hline \multicolumn{5}{|c|}{ Dependent Variable : LNFutures } \\
\hline \multicolumn{5}{|c|}{ Cash settlement } \\
\hline APHS & LNSPOT & $1.01902 * * *$ & -204.8375 & $\operatorname{ARDL}(2,3)$ \\
\hline GNP & LNSPOT & $1.000898 * * *$ & -190.4599 & $\operatorname{ARDL}(3,2)$ \\
\hline MMFS & LNSPOT & $1.009933 * * *$ & -208.6986 & $\operatorname{ARDL}(4,2)$ \\
\hline ONGC & LNSPOT & $0.953115^{* * *}$ & -135.1212 & $\operatorname{ARDL}(5,5)$ \\
\hline PWGR & LNSPOT & $1.013572 * * *$ & -188.9272 & $\operatorname{ARDL}(2,2)$ \\
\hline \multicolumn{5}{|c|}{ Physical delivery } \\
\hline ADSEZ & LNSPOT & $1.012211^{* * *}$ & -247.7038 & $\operatorname{ARDL}(4,2)$ \\
\hline APNT & LNSPOT & $0.986685 * * *$ & -127.9092 & $\operatorname{ARDL}(1,1)$ \\
\hline COAL & LNSPOT & $0.984454 * * *$ & -171.1964 & $\operatorname{ARDL}(2,12)$ \\
\hline NTPC & LNSPOT & $0.975555 * * *$ & -115.4376 & $\operatorname{ARDL}(5,6)$ \\
\hline SUNP & LNSPOT & $0.981642 * * *$ & -158.0984 & $\operatorname{ARDL}(4,4)$ \\
\hline
\end{tabular}

Price disequilibrium in spot and futures markets of single stock futures which considered in the study gets corrected in long duration. This correction helps to have balanced relationship between spot and futures markets of all companies with cent percentage, expect ONGC in cash settled companies where as in physically delivered; the stock ADSEZ is having $100 \%$ correction process, and all other stocks are nearing to $98 \%$ of correction. The result shows that the information transmission is positive for the 10 companies but the stocks with cash settled have high level transmission than the other.

The short term error correction representation is calculated using the equation (5) and which is reported in the table (6) in appendix. As the error correction coefficients are negative and significant. The stocks show a convergence or the speed of adjustment to the long run after a shock is given to the futures market. It is found that the stocks with the physical delivery are converged faster than the cash settled stocks.

It is noticed that the socks with the cash settlement have high level of information transmission while it takes more time to converge than the physical delivered stocks. In case of cash settled stocks the derivative positions is settled trough cash and not with the underlying asset, so there is enough time to arrange cash for payment till the last date of expiry. While in case of physical delivered stocks there is a need for the delivery of the underlying asset at the date of expiry so the stock have to be physically kept with the traders / investors because they are not possible to buy the stocks at the last movement of expiry.

\section{CONCLUSION}

The analysis of basis of stocks shows a convergence in the market, where the physically settled stocks are converged earlier than the cash settled stocks. Larger basis are found in most of companies with cash settled stocks, in which the convergence took only at the last date of expiry. All the stocks in the analysis shows a long run relationship, where as in cash settled stocks have high level of correction process than the physically delivered stocks. The speed of adjustment between the spot and cash market is more effective in the physical delivered stocks than the cash settled stocks, there shows a convergence of stocks after a shock in the futures market to the long run.

\section{APPENDIX}

Table 4: Error correction representation for the selected ARDL model to reflect short run relationship between single stock cash and futures prices of cash settled and physically delivered stocks

\begin{tabular}{|c|c|c|c|}
\hline & Regressor & Coefficient & T-value(Prob] \\
\hline \multicolumn{4}{|c|}{ Cash settlement } \\
\hline \multirow{2}{*}{ APHS } & LNSPOT & 10006 & $897.125 \times \times x$ \\
\hline & $\mathrm{ECM} /-1\}$ & -0.6221 & $-17.455^{x \times x}$ \\
\hline \multirow{2}{*}{ GNP } & LNSPOT & 10012 & $1390.632^{\mathrm{x} \times x}$ \\
\hline & $\mathrm{ECM} /-1\}$ & -0.6739 & $-17.684^{* \times x}$ \\
\hline \multirow{2}{*}{ MMFS } & LNSPOT & 0.9988 & $1559.30 \mathrm{~B}^{\mathrm{xNx}}$ \\
\hline & $\mathrm{ECM} / 1\}$ & -0.7235 & $-18.581^{* \times x}$ \\
\hline \multirow{2}{*}{ ONGC } & LNSPOT & 10002 & $771.025^{* \times x}$ \\
\hline & $\mathrm{ECM} /-1\}$ & -0.5246 & $-11.151^{\times x \times}$ \\
\hline \multirow{2}{*}{ PWGR } & LNSPOT & 0.9979 & $1457.700^{\times \times x}$ \\
\hline & ECM -1$\}$ & -0.4821 & $-15.361^{x \times x}$ \\
\hline \multicolumn{4}{|c|}{ Physically delivery } \\
\hline \multirow{2}{*}{ ADSEZ } & LNSPOT & 0.9995 & $188 \mathrm{~B} .602^{\mathrm{xx} x}$ \\
\hline & $\mathrm{ECM} /-1\}$ & -0.7459 & $-18.21 g^{\times x \times}$ \\
\hline \multirow{2}{*}{ APNT } & LNSPOT & 0.9995 & $1567.350^{x \times x}$ \\
\hline & ECM -1$\}$ & -0.6994 & $-23.599^{2 \times x}$ \\
\hline \multirow{2}{*}{ COAL } & LNSPOT & 10006 & $967.527 \times x \times$ \\
\hline & $\mathrm{ECM} /-1\}$ & -0.7130 & $-18.080^{x} x$ \\
\hline \multirow{2}{*}{ NTPC } & LNSPOT & 10006 & $631.192^{\times \times x}$ \\
\hline & $\operatorname{ECM}\{-1\}$ & -0.7587 & $-12.914^{x \times x}$ \\
\hline \multirow{2}{*}{ SUNP } & LNSPOT & 10007 & $1152.524^{\mathrm{xxx}}$ \\
\hline & $\mathrm{ECM} / 1\}$ & -0.6744 & $-12.62 g^{x \times x}$ \\
\hline
\end{tabular}

\section{REFERENCES}

1. Anne Neumann, B. S. (2006), Convergence of European spot market prices for natural gas? A real-time analysis of market integration using the Kalman Filter. Applied Economics Letters, 13 , pp. 727-732.

2. B.Paul, A. (1985), The role of cash settlement in Futures Contract Specification, American Enterprise Institute for Public Policy Research, pp. 271-328.

3. Barnaby, D. M. (2010), Why Have the KC Wheat Futures and Cash Prices Not Converged? Manhattan, Kansas: AG Manager, Kansas State Research \& Extension.

4. Berna Karali, K. M. (2010), The Basis Effects of Failures to Converge . Applied Commodity Price Analysis, Forecasting, and Market Risk Management (pp. 1-14). St. Louis, Missouri: http://www.farmdoc.illinois.edu/nccc134.

5. Chng, M. T. (2009), Economic linkages across commodity futures: Hedging and trading implications. Journal of Banking \& Finance, 33, pp. 958-970

6. Christian Dreger, K. K. (2007), Price convergence in the enlarged internal marke. European Economy Economic Papers, Number 292.

7. Dhuyvetter, K. C. (1992), Basis: The Cash/Futures Price Relationship. Manhattan, Kansas: Cooperative Extension

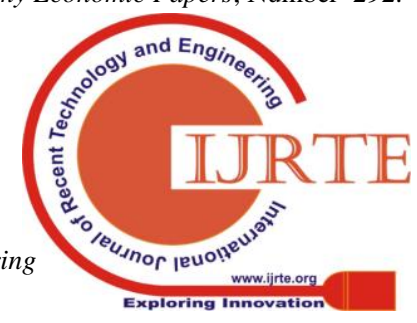


Service, Kansas State University.

8. Esma Aïmeur, G. B. (2006), Secure Anonymous Physical Delivery. IADIS International Journal on WWW/Internet, Vol. 4, No. 1, pp. 55-69.

9. Filho, T. C. (2000), Cash settlement impact on Fed Cattle Futures Contract Basis RIsk in Brazil, Rio de Janeiro 54 (2) , pp. 141-163.

10. Ghosh, S. B. (2003), Derivatives and Volatility on Indian Stock Makets. Reserve Bank of India Occasional Papers, Vol. 24, No.3, pp. 187-201.

11. Gonzalo, I. F.-F. (2010), Modelling and measuring price discovery in commodity markets. Journal of Econometrics, 158, pp. 95-107.

12. Heaney, R. (2002), Does knowledge of the cost of carry model improve commodity futures price forecasting ability?A case study using the London Metal Exchange lead contract. International Journal of Forecasting, 18 , pp. 45-65.

13. Hoffman, G. P. (2010), Price Discovery and Convergence of Futures and Cash Pricesq. Applied Commodity Price Analysis, Forecasting, and Market Risk Management, pp. 1-19, St. Louis, Missouri, $\mathrm{http} / / / \mathrm{www}$. farmdoc.illinois.edu/nccc134.

14. Hoffman-MacDonald, S. H. (2012), Price Convergence in the Lumber Futures Market. The Journal of Global Business Management , Vol.8, No.2, pp. 126-133.

15. Isemonger, A. G. (2006), The Benefits and Risks of Virtual Bidding in Multi-Settlement Markets. The Electricity Journal, pp. 26-34.

16. J.Seppi, P. K. (1992). FuturesManipulationwith "Cash Settlement". The Journal opf Finance, Vol.XLVII, No.4.

17. Jain, L. C. (2003). Indian Securities Depository System. Economic and Political weekly, Vol-XXXVIII, No.20. 